\title{
Biggest Dental Showcase comes to ExCeL, London
}

\section{This is your show so come and see what it has to offer you}

The UK's largest dental trade show, BDIA Dental Showcase, is coming to the ExCeL Centre London for three days from 6-8 October 2016. The show is massive this year and within the $17,000 \mathrm{~m}^{2}$ over 350 exhibitors are booked in to share the latest design and innovations. Thousands of dental professionals are already booked to attend. It is an unmissable opportunity to see what is new in dentistry all under one roof. You can try out the latest equipment; talk to companies; have your questions answered in person; seize the exclusive deals that are only available at Dental Showcase and acquire CPD points.

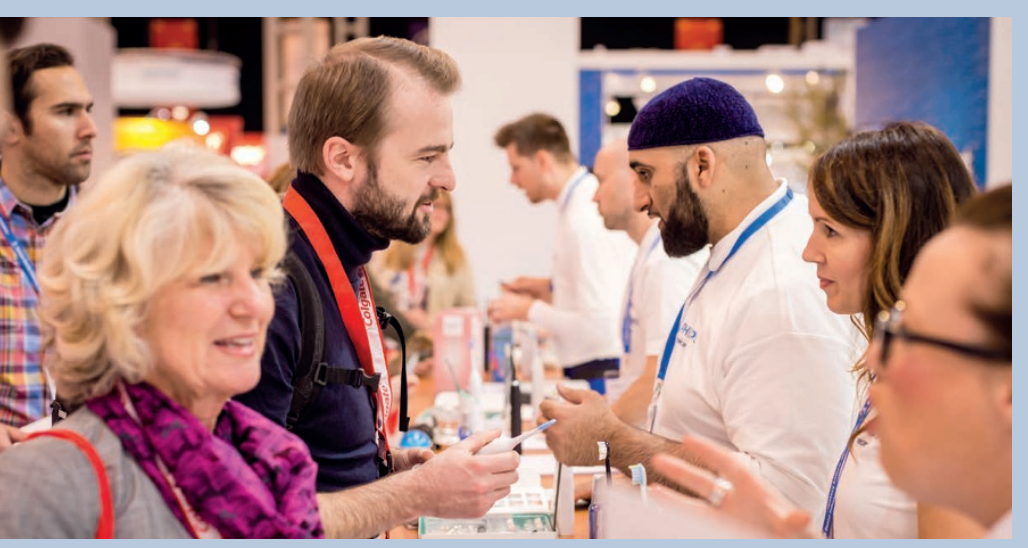

Exciting new developments for this year continue to build on the theme of 'Putting Innovation into Practice'. New features include two additional Education Theatres, which extend the seminar programme to include even more of the industry's best speakers. The Go Digital! initiative offers visitors the chance to look at transformational digital technology in the dental lab and beyond.

\section{Plan your visit}

Showcase is so big with so much to offer, it is a good idea to plan your visit in advance. Have a look at www.dentalshowcase.com where you will find all the information you need including how to register free.

The Dental Showcase 2016 mobile app, sponsored by NSK, is now available to download and it will help you to plan your visit. Featuring the exhibitor list, in addition to speakers and seminar sessions, you can 'favourite' every company and speaker you want to see. There are pages about the venue and surrounding area and the point to point map feature will help you to navigate your way around the show.

\section{Planning a purchase}

If you are planning a major purchase do your homework in advance. You could contact the companies and arrange a time to meet them on their stand and that would avoid having to wait around. Remember that many companies launch new products at Dental Showcase to attract attention to them. It could be useful to come to Showcase with a list of questions you would like to have answered. Make notes so you can compare the offers from the different companies. For complex and costly equipment such as chairside manufacturing/milling equipment and digital imaging devices, take more time to assess the advantages and benefits to the practice, any possible training requirements and the servicing and maintenance regime. Over $75 \%$ of companies attending the exhibition offer exclusive Showcase deals so buying on the day can be really advantageous.

Of course, you can now buy equipment direct from the Internet without coming to Dental Showcase. But be careful. Recent reports on counterfeit products have highlighted the need for purchasers to check the source of a product to ensure that it is properly registered for use. The BDIA are constantly working to eradicate sub-standard and counterfeit devices and instruments, and introduced the widely respected CSIDI (counterfeit and substandard instruments and devices initiative) for the protection of the dental profession and the safety of patients. This ethical approach is reassuring for delegates to Showcase who intend to make a purchase. You can have confidence, knowing that the BDIA has been at the forefront of tackling this issue on your behalf. If you are concerned about this area you could attend the Mini lecture 'Dangers of buying and selling dental equipment online' by Claire Dunne, Compliance Unit Manager for the Devices Division of the MHRA.

\section{Keep up to date}

To be successful no dental practice can stand still. Keeping up to date with current thinking and practice is essential and the two new Education Theatres this year offer an opportunity to hear the best speakers in the business. If you want to hear more about the issues in dentistry or you would like more information about some aspects of business management there are seminars to help you. 'NHS - your burning questions answered' provided by Practice Plan with an impressive panel including Dr Tony Kilcoyne, Judith Husband, Dr Len D’Cruz and Paul Worskett should provide an opportunity to give current topics in dentistry a good airing. Diamonds are forever: Practical tips for minimally invasive dentistry' with Dr Louis Mackenzie, provided by Oral-B aims to provide an overview of how the principles of minimally invasive dentistry may be applied to all aspects of dental practice. If you would like help with the management and profitability of your practice but you do not have a lot of time, the mini lecture "Dental Practice "Real" Profits and "Imaginary" Goodwill', provided by NASDAL should help you to understand the factors which influence practice profits and goodwill values.

\section{Meet and network}

Dental Showcase offers a great opportunity to catch up with friends and colleagues in dentistry and make new contacts that will be useful in the future. The Meeting and Networking Zone is designed as somewhere to hold meetings in a relaxed environment.

With so much to see at Dental Showcase you will certainly leave feeling that your visit has been informative, enjoyable and worthwhile.

BDIA Dental Showcase is taking place 6-8 October 2016 at ExCeL, London. Register online now at www.dentalshowcase.com. 